\title{
Развитие промышленности Курской области в 1934-1950 гг. в отечественной историографии 1950-x - 2000-х годов
}

\author{
Я.И. Иваненко \\ Белгородский государственный национальный исследовательский университет, \\ Россия, 308015, г. Белгород, ул. Победы, д. 85 \\ E-mail: shlif89@yandex.ru
}

\begin{abstract}
Аннотация. Статья посвящена рассмотрению степени разработанности проблем состояния и функционирования промышленности Курской области периода 1934-1950 гг. в отечественной исторической науке. В качестве библиографии в ней анализируется как советская, так и современная российская историческая литература, диссертационные исследования, в полном объеме или частично посвященные промышленности Курской области в 1934-1950 гг. Проведенный анализ данных трудов позволяет заключить, что ряд аспектов рассматриваемой проблематики является хорошо разработанным. В частности, достаточно полно изучена детальность сахарных заводов вплоть до июня 1941 г. Накоплены существенные знания относительно функционирования химических предприятий Курской области. Подробно исследован процесс восстановления промышленных предприятий союзного и республиканского подчинения региона в 1943-1945 гг. Вместе с тем в данной области знания имеются некоторые пробелы, устранение которых может стать перспективой для дальнейшего исследования.
\end{abstract}

Ключевые слова: индустриализация в СССР, промышленность регионов СССР, ЦентральноЧерноземный регион, послевоенное восстановление промышленности, отечественная историческая наука.

Для цитирования: Иваненко Я.И. 2020. Развитие промышленности Курской области в 1934-1950 гг. в отечественной историографии 1950-х - 2000-х гг. Via in tempore. История. Политология, 47 (4): 863-871. DOI: 10.18413/2687-0967-2020-47-4-863-871.

\section{Industrial development of the Kursk region in 1934-1950 in Russian historiography 1950s - 2000s}

\author{
Yaroslav I. Ivanenko \\ Belgorod National Research University, \\ 85 Pobeda St., Belgorod, 308015, Russia \\ E-mail: shlif89@yandex.ru
}

\begin{abstract}
The article is devoted to the consideration of the degree of elaboration of the problems of the state and functioning of the industry of the Kursk region in 1934-1950 in Russian historical science. As a bibliography, both Soviet and modern Russian historical literature is analyzed, in full or in part devoted to the industry of the Kursk region of the period 1934-1950. The article analyzes scientific works published both at the national and regional levels. The analysis of domestic historiography devoted to understanding the history of the industry of the Kursk region in 1934-1950, allows us to conclude that the detail of sugar factories, up to June 1941, has been sufficiently well studied. The process of restoring industrial enterprises of union and republican subordination in 1943-1945 is studied in detail. However, there are some gaps in this area of knowledge. In particular, the functioning of food (with the exception of sugar) and non-food (with the exception of chemical) industries in the Kursk region in 1934-1941 remains practically unexplored. Due attention is not paid to the recovery process at the enterprises of the food and non-food (with the exception of the chemical) industry in the region of Union and Republican
\end{abstract}


subordination in the period from 1946 to 1950 . The activity of reviving industrial enterprises of regional and district subordination in 1943-1950 has not been studied at all.

Keywords: industrialization in the USSR, industry in the regions of the USSR, the Central Black Earth Region, post-war restoration of industry, domestic historical science.

For citation: Yaroslav I. Ivanenko. 2020. Industrial development of the Kursk region in 1934-1950 in Russian historiography 1950s - 2000s. Via in tempore. History and political science, 47(4): 863-871 (in Russian). DOI: 10.18413/2687-0967-2020-47-4-863-871.

Невиданные по своим масштабам мировые войны XX века продемонстрировали, что одержать победу в них может государство, обладающее не только мощными вооруженными силами, но и достаточно высоким уровнем развития промышленности, богатыми сырьевыми запасами. Ход и итоги боевых действий также показали, что имеет значение не только состояние промышленности на конкретный период времени, но и ее мобилизационный потенциал.

Победа СССР в Великой Отечественной войне показала, что экономическая система СССР оказалась более эффективной с точки зрения организации функционирования промышленности в условиях войны.

Заметим, что проблематика развития промышленности СССР, ее работа в условиях военного времени, а также послевоенное восстановление являются достаточно разработанными в отечественной исторической науке. Так, спустя всего несколько лет после окончания Великой Отечественной войны была опубликована работа видного государственного деятеля Вознесенского Н.А., посвященная функционированию советской экономики в 1941-1945 гг. [Вознесенский, 1948]. В данной монографии описывается предвоенное состояние экономики СССР, рассматриваются вопросы ее адаптации к условиям военного времени, а также послевоенные показатели.

К работам послевоенного периода относится труд ученого-экономиста Лившиц Р.С., содержащий описание территориального размещения промышленности СССР с момента основания государства и практически до конца пятой пятилетки (1955 г.) [Лившиц, 1954]. Основной акцент в данном исследовании сделан на описании ключевых отраслей промышленности довоенных пятилеток. Уделено в нем внимание и функционированию промышленности страны в годы Великой Отечественной войны.

Еще одним из наиболее значимых трудов по обозначенной проблеме выступает работа «Советская экономика в Великой Отечественной войне 1941-1945 гг.», изданная под редакцией экономиста И.А. Гладкова [Советская экономика в Великой Отечественной войне, 1970]. В ней рассматривается функционирование различных отраслей промышленности СССР в условиях военного времени, уделяется внимание индустрии союзных республик, их месту в военной экономике государства.

В работе ученого-экономиста, государственного деятеля Чадаева Я.Е. подробно анализируется процесс создания мощной экономической базы СССР, адаптация экономики страны к реалиям войны [Чадаев, 1985]. Кроме того, автор акцентирует внимание на возрождении промышленности освобожденных от немецкой оккупации территорий.

Ряд исследований советского периода посвящен экономическому использованию Германией временно оккупированных территорий СССР в 1941-1944 гг. Среди таких работ можно выделить труд историка Немятого В.Н. [Немятый, 1982]. В данной монографии освещается деятельность советского подполья по срыву нацистских планов эксплуатации промышленности оккупированных регионов СССР.

Еще одним примером соответствующей научной литературы может служить совместный труд экономиста Загорулько М.М. и историка Юденкова А.Ф. [Загорулько, Юденков, 1980]. В данной работе ученые рассматривают вопросы эвакуации промышлен- 
ности из прифронтовых районов СССР, экономическую политику немецкой оккупационной администрации на временно оккупированных территориях и противодействие данной политике со стороны партизанского движения.

Что касается публикаций постсоветского периода, то в них также присутствует большое количество работ, в которых проводится анализ проблем функционирования промышленности СССР в 1930-1950-х гг. О важности учета экономического фактора победы в современной историографии говорит тот факт, что в фундаментальном научном труде «Великая Отечественная война 1941-1945 годов», подготовленном авторским коллективом, один из двенадцати томов посвящен экономике и оружию войны [Великая Отечественная война 1941-1945 годов. В 12 т. Т. 7. Экономика и оружие войны, 2013].

Издаются в настоящее время и совместные историко-экономические работы, посвященные рассматриваемым вопросам. Среди них можно отметить коллективную монографию «Экономический фундамент победы: параллели истории и современности» [Экономический фундамент победы: параллели истории и современности, 2015]. В данном исследовании с позиций современных экономической и исторической науки анализируется трансформация экономики СССР в преддверии и в период Великой Отечественной войны, проводятся параллели между событиями военного времени и современными кризисными ситуациями.

Вопросам функционирования промышленности СССР в предвоенные и военные годы посвящена объемная научная статья военного историка Шеповой Н.Я. [Шепова, 2011].

Вместе с тем, сосредоточившись на описании функционирования промышленности СССР 1930-1950-х гг. в целом, историки зачастую не уделяли достаточного внимания данным вопросам на уровне отдельных регионов России. Не исключением, на наш взгляд, является освещение функционирования промышленности Курской области в 1934-1950 гг. Несмотря на то, что Курская область представляла собой на данный период времени преимущественно аграрный регион, в годы первых пятилеток в ней шло интенсивное развитие индустрии. Зарождалась химическая промышленность, начинали разрабатываться обширные железорудные ресурсы Курской магнитной аномалии. По этой причине представляется обоснованным рассмотрение вопросов исследования промышленности Курской области в 1934-1950 гг. в отечественной исторической науке.

Что касается хронологических рамок исследования, то они охватывают период с июня 1934 г. по 1950 г. включительно. Выбор нижней границы обусловлен образованием в составе РСФСР Курской области. Избрание в качестве верхней границы 1950 г. было предпринято по причине того, что именно в этот год было завершено выполнение четвертого пятилетнего плана восстановления и развития народного хозяйства СССР после окончания Великой Отечественной войны.

В качестве библиографии в настоящей статье анализируется изданная как на общегосударственном, так и на региональном уровне советская и современная российская историческая литература, диссертационные исследования, в полном объеме или частично затрагивающие вопросы функционирования промышленности Курской области обозначенного периода.

Под промышленностью в настоящей статье понимается комплекс добывающих и обрабатывающих предприятий, существовавший в Курской области в 1934-1950 гг.

Отметим, что по данной проблематике в советский период был выпущен ряд обзорных работ историко-экономического характера, изданных как на региональном, так и на общесоюзном уровне. Одной из региональных работ является труд «1917-1957: статьи, воспоминания, очерки», содержащий ряд обзорных статей, характеризующих изменения в промышленности, сельском хозяйстве, народном образовании, здравоохранении и культуре Курской области за сорок лет советской власти [1917-1957: статьи, воспоминания, очерки, 1957]. В данном издании приводятся статистические данные, подтверждающие высокие темпы роста промышленности области в годы индустриализации и постепенном превращении региона из аграрного в аграрно-индустриальный [1917-1957: статьи, воспо- 
минания, очерки, 1957, с. 10-11]. Достигнутые успехи иллюстрируются путем сопоставления различных экономических показателей 1940, 1950 гг. с показателями 1913 г. [1917-1957: статьи, воспоминания, очерки, 1957, с. 10-11].

Кроме того, в работе «1917-1957: статьи, воспоминания, очерки» содержатся сведения относительно ущерба, понесенного промышленностью Курской области в ходе немецко-фашистской оккупации и восстановлении народного хозяйства, в процессе реализации четвертого пятилетнего плана [1917-1957: статьи, воспоминания, очерки, 1957, c. 13-16]. Подчеркивается, что за период с 1946 по 1950 гг. в регионе были созданы отрасли производства, которых ранее не существовало: электропромышленность, сельскохозяйственное машиностроение [1917-1957: статьи, воспоминания, очерки, 1957, с. 15].

К региональным работам советского периода, содержащим описание состояния промышленности Курской области 1934-1950 гг., относится экономико-географический очерк «Курская область» [Курская область: экономико-географический очерк, 1966]. Данное издание представляет собой сборник изложенных в научно-популярной форме статей, содержащих сведения о природе, экономическом и культурном уровне развития Курской области. Применительно к характеристике индустрии исследуемого периода в указанной работе приводятся статистические данные, свидетельствующие о количественном и качественном росте промышленных предприятий региона за годы предвоенных пятилеток [Курская область: экономико-географический очерк, 1966, с. 271-274]. Отличительной особенностью изложения материала в данной работе являются многочисленные примеры труда стахановцев, новаторов производства на конкретных предприятиях области. В экономикогеографическом очерке уделяется внимание потерям, которые понесла Курская область в ходе немецко-фашистской оккупации. Описываются восстановительные процессы в народном хозяйстве региона в послевоенный период, в частности констатируется, что уже к 1947 г. промышленность области достигла довоенного уровня, а в 1950 г. превзошла его на 28 процентов [Курская область: экономико-географический очерк, 1966, с. 278].

Еще одной работой, содержащей сведения о состоянии промышленности Курской области исследуемого периода, является краткий историко-экономический очерк «Центральное Черноземье за годы Советской власти» [Центральное Черноземье за годы Советской власти, 1967]. В указанном труде приводятся различные статистические данные, свидетельствующие о качественном и количественном росте промышленных предприятий регионов Центрального Черноземья за 50 лет, прошедшие с момента Октябрьской революции. В частности, в отношении Курской области говорится о росте числа металлообрабатывающей промышленности, возникновении новых отраслей промышленности - химической, обрабатывающей, фармацевтической [Центральное Черноземье за годы Советской власти, 1967, с. 36]. Кроме того, для характеристики индустрии Курской области исследуемого периода представляет ценность информация о размере и характере ущерба, нанесенного немецкой оккупацией, ходе и темпах послевоенного восстановительного процесса [Центральное Черноземье за годы Советской власти, 1967, с. 37-40].

К числу обзорных историко-экономических работ советского периода относится коллективная монография «Проблемы развития и размещения производительных сил Центрально-Черноземного района» [Детина и др., 1973]. Несмотря на то, что данная работа посвящена в большей степени характеристике производительных сил на начало 1970-х гг., она в весьма незначительном объеме содержит сведения, касающиеся промышленности Курской области рассматриваемого периода. В частности, говорится об активной индустриализации региона в годы первых пятилеток. При этом отмечается строительство рудника по добыче фосфоритных удобрений в Щиграх как одного из первых предприятий, построенных в Черноземье в годы второй пятилетки [Детина и др., 1973, с. 37].

Значительное место среди современных историографических работ, содержащих анализ развития промышленности Курской области довоенного периода, принадлежит коллективному труду «Курский край: годы социалистической модернизации (1921 - июнь 
1941 гг.)» [Курский край: годы социалистической модернизации (1921 - июнь 1941 гг.). 2001]. В данной работе содержится наиболее полная характеристика довоенного состояния промышленности рассматриваемого региона. Авторы дифференцированно подходят к описанию индустрии, приводя общеэкономические показатели отдельно по предприятиям союзного, республиканского, областного и районного подчинения. В целом, характеризуя состояние промышленности Курской области к 1941 г., отмечается, что ведущая роль в ней, как и ранее, осталась за пищевыми предприятиями, в то время как крупные новостройки третьей пятилетки (например, завод синтетического каучука) по причине резкого обострения международной обстановки были поставлены на консервацию [Курский край: годы социалистической модернизации (1921 - июнь 1941 гг.), 2001, с. 274-275].

Отличительной особенностью данной работы является то, что, помимо успехов в индустриальном развитии Курской области в годы первых пятилеток, в ней достаточно подробно говорится о сложностях, которые возникали по мере такого развития. Так, ученые указывают, что многочисленные трудности процесса индустриализации заключались в недостаточности финансирования строительства новых предприятий, нехватке энергоресурсов, материальном и моральном износе оборудования, дефиците квалифицированных кадров, низком качестве выпускаемой продукции [Курский край: годы социалистической модернизации (1921 - июнь 1941 гг.), 2001, с. 250-260].

Помимо работ общеэкономического характера в отечественной исторической науке существуют исследования отдельных отраслей промышленности обозначенного региона СССР. Например, история развития горнодобывающей промышленности затрагивается в совместном труде Калганова М.И., Коссовского М.А. «Великий дар природы» [Калганов, Коссовский, 1968]. Авторы создают достаточно полную картину процесса освоения Курской магнитной аномалии (в том числе в период с 1934 по 1950 гг.), характеризуя основной комплекс проведенных работ и акцентируя внимание на их исключительной важности для советского государства [Калганов, Коссовский, 1968, с. 127-137]. Особенностью данной работы является научно-популярный стиль изложения материала, изобилие геологогеографических аспектов (территориальное расположение конкретных месторождений, их размер, качество содержащихся железорудных запасов, особенности разработки).

К современной историографии освоения Курской магнитной аномалии относится научная статья Пешехоновой О.В., посвященная общей характеристике данного процесса в 1931-1945 гг. [Пешехонова, 2011]. Данная работа представляет собой хронологическое изложение ключевых событий освоения железорудных месторождений КМА. При этом автор кратко перечисляет наиболее важные виды работ, проводившиеся в исследуемый период (строительство первого рудника, открытие новых рудоносных участков, первая плавка руды и др.) [Пешехонова, 2011, с. 228-230]. Хотелось бы заметить, что в качестве источников статьи, помимо опубликованных документов, используются материалы периодической печати СССР 1930-х гг.: всесоюзный «Горный журнал», воронежская газета «Коммуна», «Курская правда».

В современной российской историографии существуют работы, касающиеся иных отраслей промышленности Курской области исследуемого периода. Так, в диссертации Миргородовой Ю.М. анализируется процесс становления и развития сахарной промышленности Курского края в 1928 - июне 1941 гг. [Миргородова, 2011]. В исследовании рассматриваются различные аспекты функционирования одной из наиболее развитых отраслей пищевой промышленности региона (техническая оснащенность предприятий, трудовые и социально-бытовые условия рабочих, роль государственных и партийных органов в организации производства). На основе исследования архивных документов Миргородова Ю.М. приходит к выводу, что сахарная промышленность играла важную роль в структуре промышленности Курской области и интенсивно развивалась в годы первых пятилеток [Миргородова, 2011, с. 167]. Однако ученый констатирует, что, несмотря на высокие тем- 
пы экономического развития, промышленность Курского края развивалась медленней, чем в соседних регионах [Миргородова, 2011, с. 167-168].

Вопросам становления и развития химической промышленности Курской области в 1930-е - начале 1990-х гг. посвятил свою диссертацию Коптев С.С. [Коптев, 2013]. Данная работа представляет собой комплексный анализ деятельности государственных и партийных органов, трудовых коллективов предприятий Курской области в исследуемый период по организации химического производства. В диссертации на основе государственных (центральных) и ведомственных архивов освещается уровень материально-технической оснащенности предприятий химической промышленности региона. Из всего объема информации, содержащейся в исследовании, к периоду 1934-1950 гг. относится характеристика таких предприятий данной отрасли, как Щигровский фосфоритный завод, Курский завод синтетического каучука. Подводя итог работе предприятий химической промышленности периода 1930-х гг., Коптев С.С. констатирует, что именно на них обязательным условием качества продукции было применение новейших научных открытий и передовых технологий [Коптев, 2013, с. 216].

К работам, содержащим анализ состояния промышленности Курской области военного периода, относится диссертация Денисовой Н.В. [Денисова, 2003]. Автор раскрывает закономерности функционирования промышленности Воронежской, Курской и Тамбовской областей в годы Великой Отечественной войны. В работе уделяется внимание эвакуации и последующему размещению в тылу ряда промышленных предприятий Курской области (завод по производству сельскохозяйственных машин им. Калинина, завод «Текстильмаш» и др.) [Денисова, 2003, с. 51-52]. Отдельный параграф указанной диссертации посвящен использованию труда иностранных военнопленных на различных промышленных объектах территорий, освобожденных от немецкой оккупации. Что касается Курской области, то указывается, что такими объектами являлись мотороремонтный завод, фармацевтический и кирпичный заводы областного центра [Денисова, 2003, с. 147].

Применительно к периоду Великой Отечественной войны особо следует отметить монографию Кононова Н.Г. «Промышленность Курской области в 1943-1945 гг.: первые шаги к возрождению» [Кононов, 2018]. В данной работе подробно описывается процесс восстановления промышленных предприятий союзного и республиканского подчинения Курской области после ее освобождения от немецкой оккупации. Ученый тщательно анализирует усилия государственных и партийных органов области, трудовых коллективов в деятельности по возрождению промышленности. Излагая материал, автор опирается на огромное количество архивных источников, хранящихся в Государственном архиве Курской области и Государственном архиве общественно-политической истории Курской области, материалы периодической печати исследуемого периода. Анализируя восстановительный процесс в регионе, автор констатирует, что ни одно из восстанавливаемых предприятий не достигло к 1945 г. довоенного уровня выпуска продукции [Кононов, 2018, с. 462]. Большой объем проделанной работы позволил Кононову Н.Г. прийти к выводу, что проблема восстановления промышленных предприятий Курской области в 1943-1945 гг. не разработана в полной мере как на общероссийском, так и на региональном уровне [Кононов, 2018, с. 21-22].

Некоторым аспектам функционирования промышленности в период нахождения Курской области в немецкой оккупации посвящена диссертация Комарова Д.Е. [Комаров, 2001]. В ней приводится экономическая характеристика территории СССР, занятой фашистской Германией, рассматриваются ход и результаты эвакуации промышленности, организованной органами советской власти из прифронтовых районов. Ученый делает акцент на реализации планов Германии по экономической эксплуатации временно оккупированных территорий СССР. Следует отметить, что автор лишь вскользь упоминает о данных процессах, происходивших в Курской области. Так, например, приводится факт использования вермахтом одной из фабрик оккупированного Курска для ремонта самолетов [Комаров, 2001, с. 125]. 
Вопросы восстановления промышленности Курской области затрагиваются в докторской диссертации Хохлова А.В. [Хохлов, 2009]. Однако в данном научном труде рассматривается вся совокупность проблем, связанных с деятельностью государственных органов, партийных и общественных организаций в возрождении самых различных сфер общественной жизни разных регионов СССР, освобожденных от оккупации, в том числе и экономических. Применительно к Курской области ученый приводит данные, согласно которым после освобождения от немецкой оккупации число промышленных предприятий региона составило 12,2 процента от их довоенного количества [Хохлов, 2009, с. 160].

Таким образом, проведенный анализ трудов, посвященных осмыслению истории промышленности Курской области 1934-1950 гг., позволяет заключить, что ряд аспектов данной проблематики является хорошо разработанным. В частности, достаточно полно изучена детальность сахарных заводов, вплоть до июня 1941 г. Накоплены существенные знания относительно функционирования химических предприятий Курской области. Подробно исследован процесс восстановления промышленных предприятий союзного и республиканского подчинения региона в 1943-1945 гг. Вместе с тем в данной области знания имеются некоторые пробелы, устранение которых может стать перспективой для дальнейшего исследования. В частности, недостаточно изученным остается функционирование предприятий пищевой (за исключением сахарной) и непищевой (за исключением химической) промышленности Курской области в 1934-1941 гг. Между тем ведущими предприятиями пищевой промышленности региона, наряду с сахарными заводами, были спиртовые. Не уделено должного внимания восстановительному процессу на предприятиях пищевой и непищевой (за исключением химической) промышленности области союзного и республиканского подчинения в период с 1946 по 1950 гг. Не изучена деятельность по возрождению промышленных предприятий областного и районного подчинения в 1943-1950 гг.

\section{Список литературы}

1. 1917-1957: статьи, воспоминания, очерки. 1957. Под ред. Т.И. Архиповой. Курск, Курское книжное издательство, 439.

2. Великая Отечественная война 1941-1945 годов. В 12 т. Т. 7. 2013. Экономика и оружие войны. Москва, Кучково поле, 864.

3. Вознесенский Н.А. 1948. Военная экономика СССР в период Отечественной войны. Москва, Гос. издательство политической литературы, 192.

4. Денисова Н.В. 2003. Промышленность областей Центрального Черноземья России в годы Великой Отечественной войны. Дисс. ... канд. ист. наук. Воронеж, 189.

5. Детина С.И., Овчинский Н.В., Шахова О.Т. 1973. Проблемы развития и размещения производительных сил Центрально-Черноземного района. Москва, Мысль, 183.

6. Загорулько М.М., Юденков А.Ф. 1980. Крах плана «Ольденбург» (о срыве экономических планов фашистской Германии на временно оккупированной территории СССР). Москва, Экономика, 376.

7. Калганов М.И., Коссовский М.А. 1968. Великий дар природы. Москва, Недра, 255.

8. Комаров Д.Е. 2001. Эксплуатация фашистской Германией экономического потенциала временно оккупированных территорий СССР (1941-1944 гг.). Дисс. ... канд. ист. наук. Смоленск, 281.

9. Кононов Н.Г. 2018. Промышленность Курской области в 1943-1945 гг.: первые шаги к возрождению. Курск, ИП Бабкина Г.П., 463.

10. Коптев С.С. 2013. Становление и развитие предприятий химической промышленности Курской области в 1930-е - начале 1990-х гг. Дисс. ... канд. ист. наук. Курск, 260.

11. Курский край: годы социалистической модернизации (1921 - июнь 1941 гг.). Научнопопулярная серия в 20 томах. Т. 10. 2001. Курск: Издательство Курского государственного педагогического университета, 400.

12. Курская область: экономико-географический очерк. 1966. Воронеж, ЦентральноЧерноземное книжное издательство, 480. 
13. Лившиц Р.С. 1954. Очерки по размещению промышленности СССР. Москва, Гос. издательство политической литературы, 360.

14. Миргородова Ю.М. 2011. Становление и развитие советской сахарной промышленности (на материалах Курского края: 1928 г. - июнь1941 гг.). Дисс. ... канд. ист. наук. Курск, 232.

15. Немятый В.Н. 1982. В борьбе за срыв грабительских планов фашистской Германии. Киев, Издательство политической литературы Украины, 230.

16. Пешехонова О.В. Освоение Курской магнитной аномалии за 1931-1945 гг. Ученые записки. Электронный научный журнал Курского государственного университета. 2011. 3-2: 226-230.

17. Хохлов А.В. 2009. Восстановительный процесс в освобожденных районах РСФСР в годы Великой Отечественной войны и послевоенный период (1941-1953 гг.). Дисс. ... докт. ист. наук. Воронеж, 456.

18. Центральное Черноземье за годы Советской власти (краткий историко-экономический очерк). 1967. Под ред. А.А. Глухова. Воронеж, Издательство Воронежского университета, 247.

19. Шепова Н.Я. 2011. Был ли готов СССР к ведению Великой Отечественной войны? Вестник МГИМО Университета. 2: 96-108.

20. Экономический фундамент победы: параллели истории и современности. 2015. Под ред. И.В. Караваевой. Москва, Институт экономики Российской академии наук, 344.

\section{References}

1. 1917-1957: stat'i, vospominanija, ocherki [1917-1957: articles, memoirs, essays]. 1957. Pod red. T.I. Arhipovoj. Kursk, Kurskoe knizhnoe izdatel'stvo, 439 (in Russian).

2. Velikaja Otechestvennaja vojna 1941-1945 godov. V 12 t. T. 7. 2013. Jekonomika i oruzhie vojny [The Great Patriotic War of 1941-1945. In 12 volumes. Volume 7. Economy and weapons of war]. Moskva, Kuchkovo pole, 864 (in Russian).

3. Voznesenskij N.A. 1948. Voennaja jekonomika SSSR v period Otechestvennoj vojny [The military economy of the USSR during the Patriotic War]. Moskva, Gos. izdatel'stvo politicheskoj literatury, 192 (in Russian).

4. Denisova N.V. 2003. Promyshlennost' oblastej Central'nogo Chernozem'ja Rossii v gody Velikoj Otechestvennoj vojny [Industry of the regions of the Central Black Earth Region of Russia during the Great Patriotic War]. Diss. ... kand. ist. nauk. Voronezh, 189 (in Russian).

5. Detina S.I., Ovchinskij N.V., Shahova O.T. 1973. Problemy razvitija i razmeshhenija proizvoditel'nyh sil Central'no-Chernozemnogo rajona [Problemy razvitija i razmeshhenija proizvoditel'nyh sil Central'no-Chernozemnogo rajona]. Moskva, Mysl', 183 (in Russian).

6. Zagorul'ko M.M., Judenkov A.F. 1980. Krah plana «Ol'denburg» (o sryve jekonomicheskih planov fashistskoj Germanii na vremenno okkupirovannoj territorii SSSR) [The collapse of the «Oldenburg» plan (on the disruption of the economic plans of Nazi Germany in the temporarily occupied territory of the USSR)]. Moskva, Jekonomika, 376 (in Russian).

7. Kalganov M.I., Kossovskij M.A. 1968. Velikij dar prirody [Great gift of nature]. Moskva, Nedra, 255 (in Russian).

8. Komarov D.E. 2001. Jekspluatacija fashistskoj Germaniej jekonomicheskogo potenciala vremenno okkupirovannyh territorij SSSR (1941-1944 gg.) [Exploitation by fascist Germany of the economic potential of the temporarily occupied territories of the USSR (1941-1944)]. Diss. ... kand. ist. nauk. Smolensk, 281 (in Russian).

9. Kononov N.G. 2018. Promyshlennost' Kurskoj oblasti v 1943-1945 gg.: pervye shagi k vozrozhdeniju [Industry of the Kursk region in 1943-1945: the first steps towards revival]. Kursk, IP Babkina G.P., 463 (in Russian).

10. Koptev S.S. 2013. Stanovlenie i razvitie predprijatij himicheskoj promyshlennosti Kurskoj oblasti v 1930-e - nachale 1990-h gg. [Formation and development of enterprises of the chemical industry of the Kursk region in the 1930s - early 1990s.]. Diss. ... kand. ist. nauk. Kursk: 260 (in Russian).

11. Kurskij kraj: gody socialisticheskoj modernizacii (1921 - ijun' 1941 gg.) [Kursk Territory: the years of socialist modernization (1921 - June 1941)]. Nauchno-populjarnaja serija v 20 tomah. T. 10. 2001. Kursk: Izdatel'stvo Kurskogo gosudarst-vennogo pedagogicheskogo universiteta, 400 (in Russian).

12. Kurskaja oblast': jekonomiko-geograficheskij ocherk [Kursk region: economic and geographical essay]. 1966. Voronezh, Central'no-Chernozemnoe knizhnoe izdatel'stvo, 480 (in Russian). 
13. Livshic R.S. 1954. Ocherki po razmeshheniju promyshlennosti SSSR [Essays on the location of the USSR industry]. Moskva, Gos. izdatel'stvo politicheskoj literatury, 360 (in Russian).

14. Mirgorodova Ju.M. 2011. Stanovlenie i razvitie sovetskoj saharnoj promyshlennosti (na materialah Kurskogo kraja: 1928 g. - ijun'1941 gg.) [Formation and development of the Soviet sugar industry (based on materials from the Kursk territory: 1928 - June 1941)]. Diss. ... kand. ist. nauk. Kursk, 232 (in Russian).

15. Nemjatyj V.N. 1982. V bor'be za sryv grabitel'skih planov fashistskoj Germanii [In the struggle to thwart the predatory plans of Nazi Germany]. Kiev: Izdatel'stvo politicheskoj literatury Ukrainy, 230 (in Russian).

16. Peshehonova O.V. Osvoenie Kurskoj magnitnoj anomalii za 1931-1945 gg. [Development of the Kursk Magnetic Anomaly in 1931-1945]. Uchenye zapiski. Jelektronnyj nauchnyj zhurnal Kurskogo gosudarstvennogo universiteta. 2011. 3-2: 226-230 (in Russian).

17. Hohlov A.V. 2009. Vosstanovitel'nyj process $v$ osvobozhdennyh rajonah RSFSR v gody Velikoj Otechestvennoj vojny i poslevoennyj period (1941-1953 gg.) [The recovery process in the liberated regions of the RSFSR during the Great Patriotic War and the post-war period (1941-1953)]. Diss. ... dokt. ist. nauk. Voronezh, 456 (in Russian).

18. Central'noe Chernozem'e za gody Sovetskoj vlasti (kratkij istoriko-jekonomicheskij ocherk) [Central Black Earth Region during the years of Soviet power (a short historical and economic essay)]. 1967. Pod red. A.A. Gluhova. Voronezh, Izdatel'stvo Voronezhskogo universiteta, 247 (in Russian).

19. Shepova N.Ja. 2011. Byl li gotov SSSR k vedeniju Velikoj Otechestvennoj vojny? [Was the USSR ready to wage the Great Patriotic War?]. Vestnik MGIMO Universiteta. 2: 96-108 (in Russian).

20. Jekonomicheskij fundament pobedy: paralleli istorii i sovremennosti [The economic foundation of victory: parallels between history and modernity]. 2015. Pod red. I.V. Karavaevoj. Moskva, Institut jekonomiki Rossijskoj akademii nauk, 344 (in Russian).

\section{ИНФОРМАЦИЯ ОБ АВТОРЕ}

Иваненко Ярослав Игоревич, аспирант кафедры российской истории и документоведения Белгородского государственного национального исследовательского университета, г. Белгород, Россия

\section{INFORMATION ABOUT THE AUTHOR}

Yaroslav I. Ivanenko, postgraduate student of the Department of Russian history and pre-study Belgorod State National Research University, Belgorod, Russia 